\title{
Experimental Study on Children Movement in a Stairwell of a Teaching Building
}

\author{
F.Z Huo ${ }^{1,2}$, W.G Song ${ }^{1}{ }^{* *}$, X.D Liu ${ }^{1}$, S.C Cao ${ }^{1}$, Y.P Zeng ${ }^{1}$, K.M. Liew ${ }^{2}$ \\ ${ }^{1}$ State Key Laboratory of Fire Science, University of Science and Technology, China \\ ${ }^{2}$ Department of Architecture and Civil Engineering, City University of Hong Kong, China
}

Copyright (C) 2015 Horizon Research Publishing All rights reserved.

\begin{abstract}
The purpose of this study is to investigate the movement characteristics of children in building stairs. In this study, four different experimental scenarios were conducted in a stairwell of a teaching building. The movement processes of children in the stairs were recorded by video cameras. The movement parameters of children in stairs were extracted and analyzed based on the recording data, including speed comparison between different scenarios, individual speed with respect to time and the fundamental diagrams. The results demonstrate that the gender and the movement type could influence the speed of children. The decreased trend of speed with the increase of density agrees with the results of adults, and the density of children on stairs in evacuation process could reach $6.4 \mathrm{per} / \mathrm{m}^{2}$.
\end{abstract}

Keyword Evacuation, Stairwell, Children, Movement Speed, Fundamental Diagram

\section{Introduction}

It is important to understand human evacuation dynamics and performances when designing and evaluating buildings to reduce the risk of occupants in emergency situations, such as fire. Stairs are significant means of evacuation in multi-storey and high-rise buildings, and the evacuation performance of stairs is related to the life safety of occupants in emergency [1]. Therefore, it is essential to investigate the factors that affect the escape efficiency in stairwell. The characteristics of pedestrian and the characteristics of staircase are two elements that affect pedestrian's walking speed on stairs [2]. Numerous factors affect people's behavior on stairs and the differences in average walking speed on stairs both upward and downward have been presented [1, 3-6]. However, very few studies can be found providing information on evacuation dynamics of children [7, 8]. The practical data of children movement characteristics in stairwell are helpful and necessary for stair design and evacuation management. Therefore, in this paper, we present our experimental study on children movement in a stairwell of a teaching building, and four different experimental scenarios are conducted and the movement characteristics of children on stairs are discussed.

\section{Materials and Methods}

\subsection{Characteristics of Stairs}

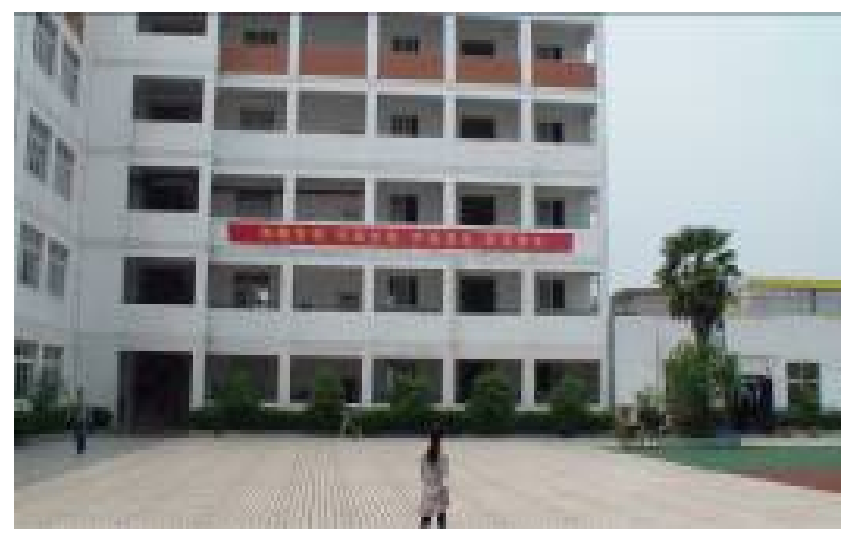

(a)

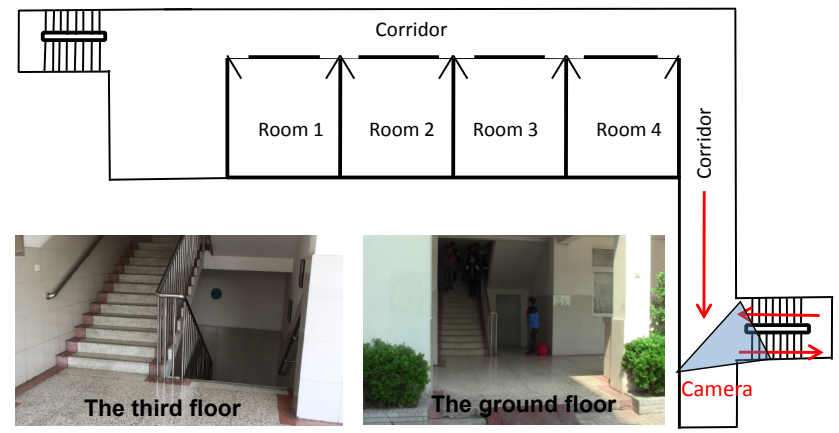

(b)

Figure 1. Illustrations of the experiments. (a)the view of the building; (b)structure diagram of the building.

The experiments were conducted in a teaching building in Yangzhou, China on May 16th, 2014, as shown in Fig. 1(a). The teaching building has five floors above ground and four 
classrooms in each floor with two stairs in each side, as shown in Fig. 1(b). The width of the stairs is $1.53 \mathrm{~m}$, and the height and depth of stair tread are $0.15 \mathrm{~m}$ and $0.28 \mathrm{~m}$ respectively. The width and depth of mid-landing between two floors are $3.46 \mathrm{~m}$ and $1.65 \mathrm{~m}$ respectively. There are 24 steps between two floors and 12 steps in each flight. The stairs are identical on each floor and all the experiments were conducted on one of the two stairs, as the red arrow pointed in Fig. 1(b), each experimental scenario was conducted once.

\subsection{Experimental Procedures}

The participants of the experiments are students of the elementary school from fourth grade to sixth grade. The experiments include four different scenarios: 1) Students from different floors walk down the stairs in order; 2) Students walk up the stairs in order; 3) Students from different floors evacuate through the stairs; 4) Students walk up the stairs freely. Three digital cameras were placed on the ground floor, the third floor and the fourth floor to record the movement processes of children when they walk through the stairs, as shown in Fig. 1(b).

In scenario one, the students left the classrooms when they heard the instruction that the experiment starts, and then they followed their teachers in order and walked to the stairs and the experiment scenario ended until all participants left the building. The movements of 195 students who walked down the stairs were recorded. In scenario two, all students who have participated in scenario one walked up the stairs by following their teachers in order and the experiment scenario ended until all participants returned their classrooms. The movements of 196 students who walked up the stairs were recorded. In scenario three, the students left the classrooms when they heard the instruction that the experiment starts, then they need evacuate the building as soon as possible without the teachers' leading, and the experiment scenario ended until all participants left the building. The movements of 339 students who walked down the stairs were recorded. In scenario four, all students who have participated in scenario three walked up the stairs freely without teachers' leading, and the experiment scenario ended until all participants returned their classrooms. The movements of 239 students who walk up the stairs were recorded.

\subsection{Data Analysis}

The movement processes of children through stairs were recorded by digital cameras. In regard to the video data of pedestrian movement, two typical methods were used to get the detailed movement characteristics; one is the digital image processing method $[9,10]$, the other is the manual processing method $[1,11]$. The digital image processing method has high efficiency to get the detailed pedestrian movement parameters, but this method could not identify individual characteristics, such as gender, posture and so on. Besides, the position and angle of the cameras are limited if the digital image processing method is used. Therefore, we adopt the manual processing method to get detailed movement characteristics of children through stairs. The times of each participant entered and left the stair landings were extracted and recorded. Thus, the speed and density of children on stair landings can be calculated.

\section{Results and Discussion}

This section discusses the children's movement characteristics on the stairs, including speed comparison between different experimental scenarios and the fundamental diagrams on the stair landings for different scenarios.

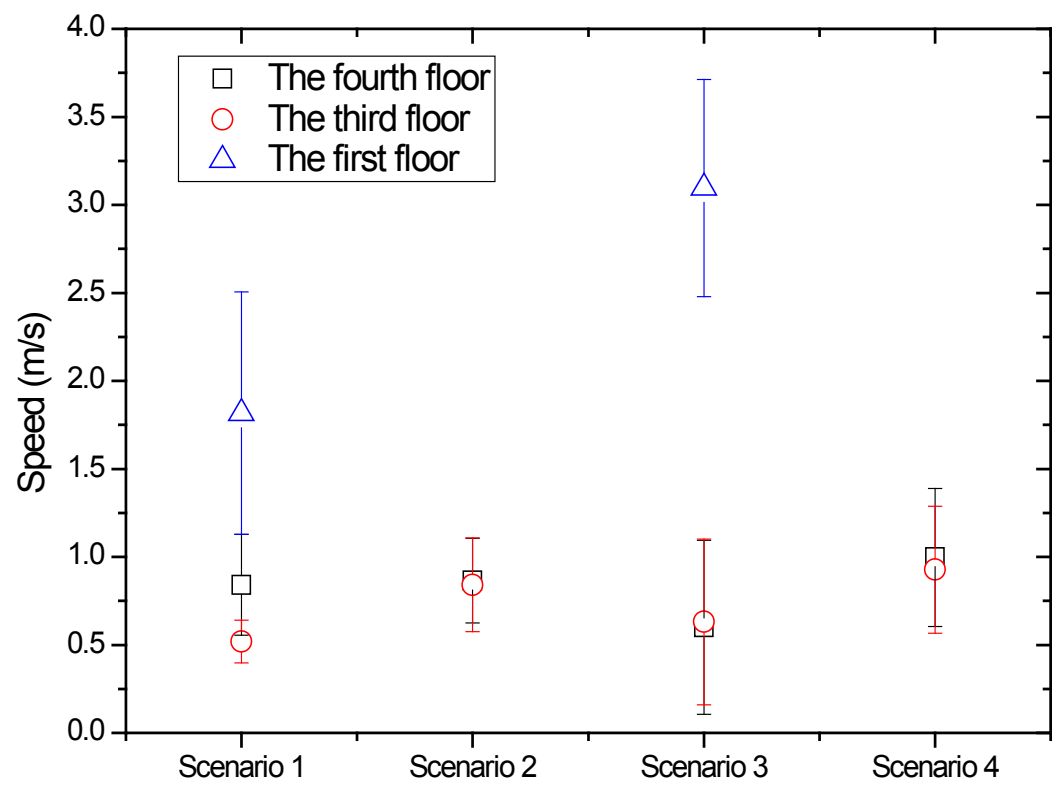

Figure 2. Average speed of children in different scenarios and different stair landings. 


\subsection{Speed Comparison}
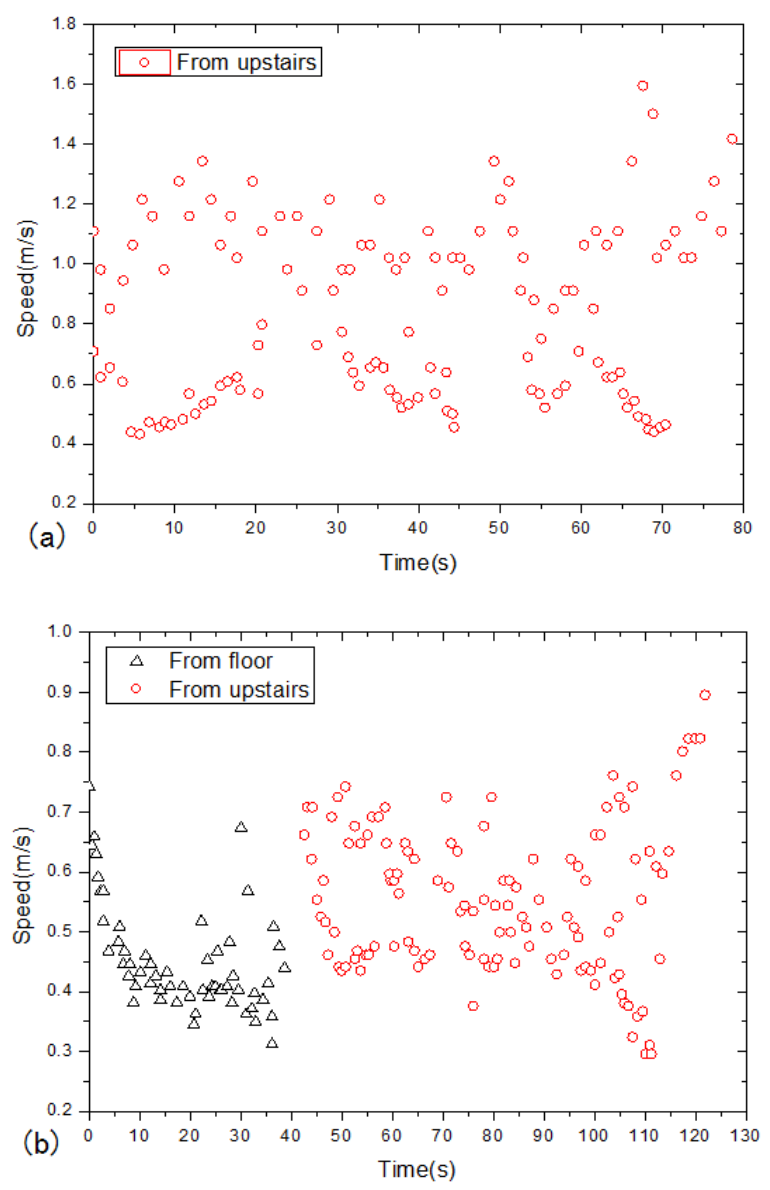

Figure 3. The individual speed with respect to time of individuals exiting the stair landings in scenario one. (a) The individual speed on the fourth stair landing; (b) The individual speed on the third stair landing.

This subsection investigates the speed comparison between different experimental scenarios. The speed of each child walking on the stair landings can be calculated by the ratio between the travel distance on stair landings and the time each child spent on the travel distance. Although each child has a different walking distance on stair landings, we assumed that the children walked on stair landings with a constant value for simplicity. For the travel distance of children on the stair landings of the fourth floor and the third floor, the travel distance of child on stair landings from upstairs for scenario one and three and to upstairs for scenario two and four is $2.46 \mathrm{~m}$, while the travel distance of child on stair landings from floors for scenario one and three and to floors for scenario two and four is $2.34 \mathrm{~m}$. For the travel distance of children on the first floor, the travel distance of child is $4.8 \mathrm{~m}$.

Fig. 2 shows the average speed of children in different scenarios and different stair landings. It can be seen that in scenario one, the average speed of children on the fourth floor is higher than that on the third floor, while in scenario two, three and four, the average speed of children on the fourth floor and third floor are almost the same. The reason for the difference in scenario one might be that when the children walk through the fourth stair landing, there are no obstructions on stairs in front of them, however when the children from upstairs walk through the third stair landing, the children from the third floor have entered the stairs in relatively low speeds, as shown in Fig. 3(a) and (b), which caused the low speed of children on the third stair landings. The average speed of children on the first floor in scenario one and three are higher than that on the fourth and third floor, especially for scenario three, the average speed of children reaches to $3.1 \mathrm{~m} / \mathrm{s}$. This might be caused by the fact that the width of stair landing on first floor is relatively larger and the stair landing is adjacent to the outdoor open area. The children could keep higher speeds through stair landing of the first floor, which could reduce the possibility of congestion on the exit of stairs and enhance the evacuation efficiency. Besides, it can also be found that the upward speeds of children in regard to scenario two and four are higher than the downward speeds of children in regard to scenario one and three. The main reason accounting for the results might be that the higher density and merging behavior between children from upstairs and floor on stair landings reduced the speed of children in scenario one and three, which can be clearly seen in Fig. 5. The detailed relationships between children' speed and density will be presented in next subsection.
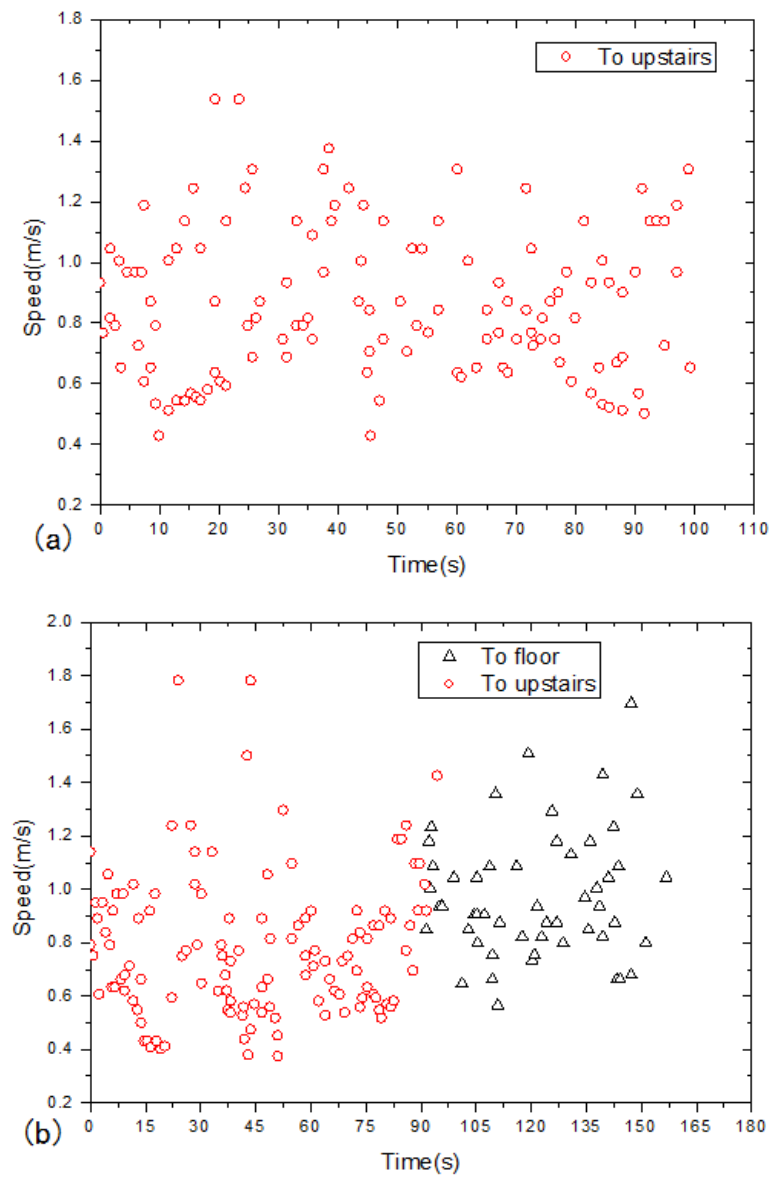

Figure 4. The individual speed with respect to time of individuals exiting the stair landings in scenario two. (a) Individual speed on the fourth stair landing; (b) Individual speed on the third stair landing. 
Table 1. Speed comparison for the gender and movement type

\begin{tabular}{|c|c|c|c|c|c|c|c|c|c|}
\hline \multirow{3}{*}{ Scenario } & \multirow{3}{*}{ Floors } & \multicolumn{4}{|c|}{ Gender } & \multicolumn{4}{|c|}{ Movement type } \\
\hline & & \multicolumn{2}{|c|}{ Boys } & \multicolumn{2}{|c|}{ Girls } & \multicolumn{2}{|c|}{ From/To upstairs } & \multicolumn{2}{|c|}{ From/To floor } \\
\hline & & Mean & $\mathrm{SD}$ & Mean & SD & Mean & $\mathrm{SD}$ & Mean & SD \\
\hline \multirow{3}{*}{ Scenario one } & Fourth & 0.58 & 0.12 & 1.04 & 0.20 & 0.84 & 0.29 & -- & -- \\
\hline & Third & 0.46 & 0.08 & 0.57 & 0.13 & 0.55 & 0.12 & 0.45 & 0.09 \\
\hline & First & 1.83 & 0.75 & 1.80 & 0.64 & -- & -- & -- & -- \\
\hline \multirow{2}{*}{ Scenario two } & Fourth & 0.70 & 0.14 & 0.99 & 0.23 & 0.87 & 0.24 & -- & -- \\
\hline & Third & 0.73 & 0.22 & 0.93 & 0.27 & 0.78 & 0.26 & 0.96 & 0.23 \\
\hline \multirow{3}{*}{ Scenario three } & Fourth & 0.64 & 0.49 & 0.56 & 0.50 & 0.58 & 0.52 & 0.62 & 0.47 \\
\hline & Third & 0.71 & 0.60 & 0.55 & 0.26 & 0.64 & 0.49 & 0.61 & 0.42 \\
\hline & First & 3.26 & 0.67 & 2.93 & 0.51 & -- & -- & -- & -- \\
\hline \multirow{2}{*}{ Scenario four } & Fourth & 1.07 & 0.42 & 0.94 & 0.36 & 0.87 & 0.38 & 1.12 & 0.36 \\
\hline & Third & 0.95 & 0.40 & 0.91 & 0.33 & 0.90 & 0.35 & 0.99 & 0.38 \\
\hline
\end{tabular}

Table. 1 presents the speed comparison for the gender and movement type in different scenarios and different floors. It is found that in scenario one and two, the average speed of girls is higher than the boys both on fourth and third stair landings. Observing the video tapes of the experimental scenarios, we found that in the movement process for scenario one and two, most of the girls walk inside the stairs and the boys walk outside the stairs. The travel distance for the child walking inside is different from the child walking outside; however, the travel distance in our calculation of speed is regarded as a constant value, which caused the average speed of girls higher than boys. The results in scenario three and four are different from the scenario one and two in regard to the speed comparisons between boys and girls because that in scenario three and four the children walk through stairs in disorder. The average speed of boys is higher than the girls in stair landings in scenario three and four, which agree with the observational results for adults obtained by Fujiyama and Tyler [2] and Lam [5]. The movement type of children refers to the movement process on stair landings. With respect to scenario one and three, the children walk down the stairs from different floors and two streams of pedestrian enter the stair landings, one stream enter the stair landing from upstairs and the other stream enter the stair landing from the fourth floor. The movement processes of children in scenario two and four are reverse from the scenario one and three. It can be found that for scenario two on third stair landing and scenario four on fourth and third stair landing, the mean movement speeds for children from upstairs are lower than that from floor. Besides, the movement speeds for children to upstairs are lower than that to floor for scenario three on fourth stair landing. One possible explanation for the results might be due to the turning behavior on stair landings for children from upstairs and to upstairs. However, for scenario one on third stair landing, the mean movement speeds for children from upstairs are higher than that from floor, and for scenario three on third stair landing, the average movement speeds between children from upstairs and from floor are almost the same. As can be found from Fig. 5(b), the merging behavior between the children from upstairs and floor and higher density on stair landings make the children move in relatively lower speeds.
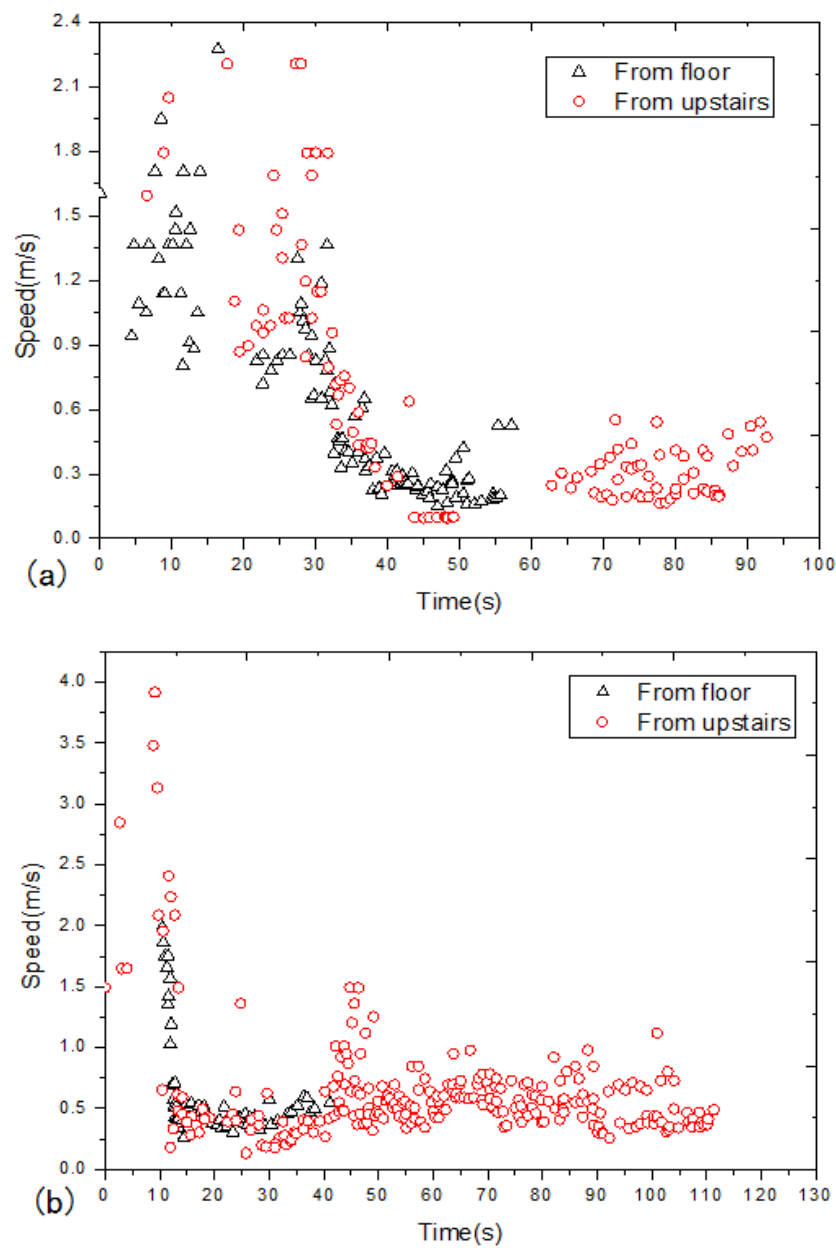

Figure 5. The individual speed with respect to time of individuals exiting the stair landings in scenario three. (a) Individual speed on the fourth stair landing; (b) Individual speed on the third stair landing.

Fig. 3-Fig. 6 show the individual speed with regard to the 
time of individuals exiting the fourth and third stair landings for scenario one to four. The time starts when the first child enters the stair landings. As can be seen from Fig. 5, the speeds of children on stair landings show large variation and the large standard deviation can also be seen in Fig. 2 for scenario three. The first few children moved faster, but the speeds of children decreased when more children entered the stair. The fastest speed of children on the fourth (third) stair landings was $2.21 \mathrm{~m} / \mathrm{s}(3.91 \mathrm{~m} / \mathrm{s})$ and the slowest speed on the same stair landings was $0.095 \mathrm{~m} / \mathrm{s}(0.13 \mathrm{~m} / \mathrm{s})$. The possible explanation of the results might be that the increased pedestrian density on the stair landings affected the evacuation speeds of children.
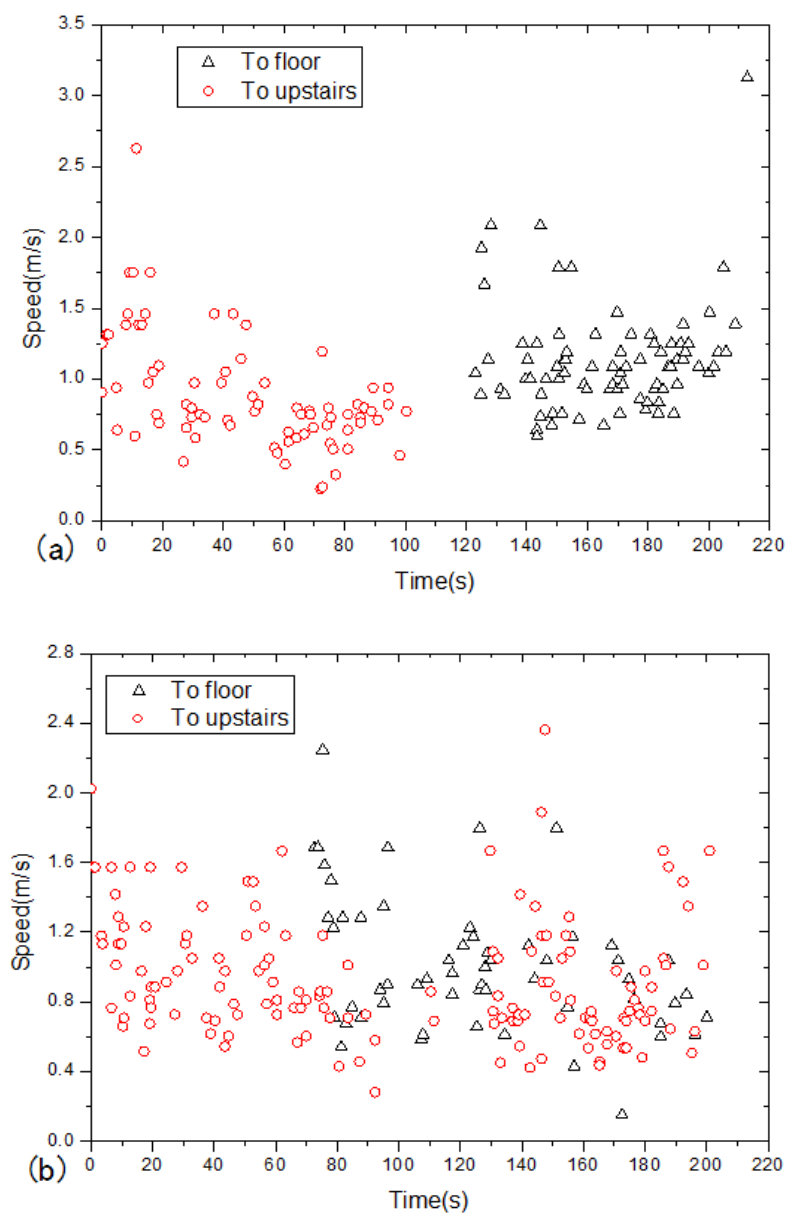

Figure 6. The individual speed with respect to time of individuals exiting the stair landings in scenario four. (a) Individual speed on the fourth stair landing; (b) Individual speed on the third stair landing.

\subsection{Fundamental Diagram}

The fundamental diagram refers to the relation between density and flow or speed, and this relation quantifies the capacity of pedestrian facilities and the rating of evacuation routes $[12,13]$. Moreover, the fundamental diagram can also be used to the verification of models for pedestrian movement, and is a principal validation whether the model is suitable for the representation of pedestrian flows.
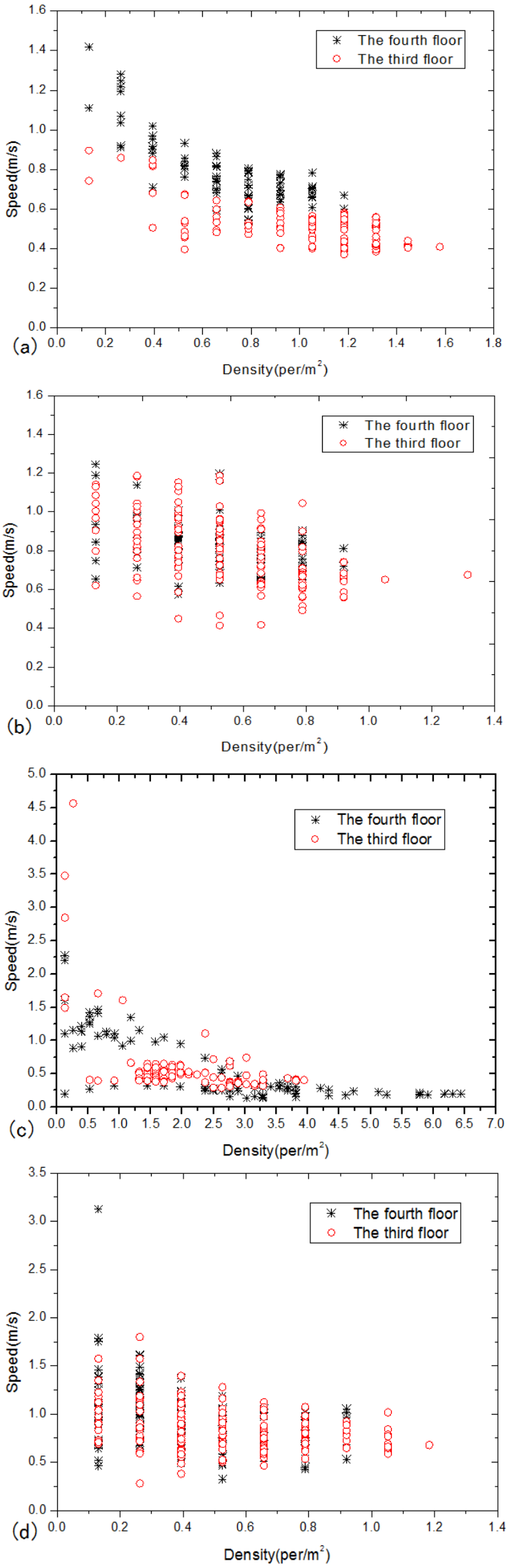

Figure 7. Fundamental diagrams of children movement on stair landings for different scenarios. (a) Scenario one; (b) Scenario two; (c) Scenario three; (d) Scenario four. 
Fig. 7 shows the experimental relation between density and speed for children movement in different experimental scenarios. It can be found that in the four scenarios the speeds of children decrease with the increase of density, which agree with the experimental results for adults obtained by Fang [1]. It should be noted that the densities of children in scenario two and four are mainly less than $1.20 \mathrm{per} / \mathrm{m}^{2}$. The reason accounting for the low density for scenario two and four might be that the time intervals between individuals are large when children walk up the stairs, as shown in Fig. 4 and Fig. 6, and there are two possible exits for children on stair landings when they walk up the stairs. Therefore, the higher density on stair landings for children walking up the stairs can hardly formed during the movement processes. Comparing the scenario one and three, it is found that the density for scenario three could reach $6.40 \mathrm{per} / \mathrm{m}^{2}$, but the density for scenario one could only reach $1.58 \mathrm{per} / \mathrm{m}^{2}$. The results reflect the fact that in the evacuation process, the desired speed of child is higher and the congestion could be easily formed on stairs, especially on the stair landings where two stream of children merging. The stampede accident on building stairs is based on the formation of congestion; therefore decreasing the density of children on stairs is an efficiency method to reduce the possibility of stampede accident and the movement process of children in scenario one could enhance the safety of children on building stairs.

\section{Conclusions}

In this paper, we conducted experiments on children movement in a stairwell of a teaching building. The experimental processes of children in four different scenarios were recorded and the movement characteristics were extracted from the recorded data. The speed comparison between different experimental scenarios and different floors were presented. It is found that the average speeds of children on the first floor are higher than that on the fourth and third floor in scenario one and three. The experimental results also demonstrate that the upward speeds of children are higher than the downward speeds. Then we analyzed the influences of gender and movement type on children' speed. The average speed of boys is higher than the girls when the movement process progresses without the teachers' leading. The turning behavior might influence the movement speeds for children from/to upstairs and from/to floor. For the evacuation process, a typical phenomenon was found that the first few children moved faster and as more children entered the stair the speeds of children decreased due to the increased pedestrian density. The fundamental diagrams of children on stair landings show that the decreased trend of speed with the increase of density agrees with the results for adults. Moreover, the density of children on stairs in evacuation process could reach $6.40 \mathrm{per} / \mathrm{m}^{2}$, which increases the possibility of stampede of children on stairs. The results are important for developing and improving pedestrian movement models for children. The basic parameters such as the downward and upward speed, the relation between speed and density, as well as the influencing factors, could provide a reference for the construction of computer egress models and are useful for building designers. However, it should be noted that the experiments were conducted in one teaching building, and more experiments on different buildings are needed for further understanding on the subject and for future models to describe children's evacuation pattern and behavior on building stairs.

\section{Acknowledgements}

The study is supported by National Basic Research Program of China (No. 2012CB719705), National Natural Science Foundation of China (No.51178445 and 51120165001), Specialized Research Fund for the Doctoral Program of Higher Education of China(No.20133402110009), Key Technologies R\&D Program of China during the 12th Five-year Plan Period (2012BAK13B01) and the Fundamental Research Funds for the Central Universities (WK2320000014).

\section{REFERENCES}

[1] Fang, Z.M., et al., Experimental study on evacuation process in a stairwell of a high-rise building. Building and Environment, 2012. 47: p. 316-321.

[2] Fujiyama, T. and N. Tyler, Predicting the walking speed of pedestrians on stairs. Transportation Planning and Technology, 2010. 33(2): p. 177-202.

[3] Peacock, R.D., B.L. Hoskins, and E.D. Kuligowski, Overall and local movement speeds during fire drill evacuations in buildings up to 31 stories. Safety Science, 2012. 50(8): p. $1655-1664$

[4] Burghardt, S., A. Seyfried, and W. Klingsch, Performance of stairs - Fundamental diagram and topographical measurements. Transportation Research Part C: Emerging Technologies, 2013(0).

[5] Lam, J.H.T., et al., Experimental study on upward movement in a high-rise building. Safety Science, 2014. 70(0): p. 397-405.

[6] Kretz, T., et al., Upstairs walking speed distributions on a long stairway. Safety Science, 2008. 46(1): p. 72-78.

[7] Kholshchevnikov, V.V., et al., Study of children evacuation from pre-school education institutions. Fire and Materials, 2012. 36(5-6): p. 349-366.

[8] Larusdottir, A.R. and A.S. Dederichs, Evacuation of Children: Movement on Stairs and on Horizontal Plane. Fire Technology, 2012. 48(1): p. 43-53.

[9] Liu, X., W.G. Song, and J. Zhang, Extraction and quantitative analysis of microscopic evacuation characteristics based on digital image processing. Physica a-Statistical Mechanics and Its Applications, 2009. 388(13): p. $2717-2726$. 
[10] Tian, W., et al., Experimental study of pedestrian behaviors in a corridor based on digital image processing. Fire Safety Journal, 2012. 47: p. 8-15.

[11] Ma, J., et al., Experimental study on an ultra high-rise building evacuation in China. Safety Science, 2012. 50(8): p. $1665-1674$.
[12] Seyfried, A., et al., The fundamental diagram of pedestrian movement revisited. Journal of Statistical Mechanics: Theory and Experiment, 2005.

[13] Zhang, J., et al., Ordering in bidirectional pedestrian flows and its influence on the fundamental diagram. Journal of Statistical Mechanics-Theory and Experiment, 2012. 